\title{
Long-term results of chemoradiation plus pulsed- dose-rate brachytherapy boost in anal canal carcinoma: A mono-institutional retrospective analysis
}

\author{
Alessandra Arcelli, MD!, Milly Buwenge, MSc', Gabriella Macchia, MD², Silvia Cammelli, MD', Francesco Deodato, MD² \\ Savino Cilla, PhD³, Andrea Galuppi, MD', Valeria Panni, MDl, Gian Carlo Mattiucci, MD4, Luca Tagliaferri, MD*, \\ Alessio G. Morganti, MD* \\ 'Department of Experimental, Diagnostic, and Specialty Medicine - DIMES, University of Bologna, S. Orsola-Malpighi Hospital, Bologna, \\ Italy, 2Radiation Oncology Unit, Research, and Care Foundation "Giovanni Paolo II", Catholic University of Sacred Heart, Campobasso, Italy, \\ ${ }^{3}$ Medical Physics Unit, Research, and Care Foundation "Giovanni Paolo Il", Catholic University of Sacred Heart, Campobasso, Italy. \\ ${ }^{4}$ Fondazione Policlinico Universitario "A. Gemelli" IRCCS, Roma, Italy \\ *Luca Tagliaferri and Alessio G. Morganti contributed equally to this work.
}

\begin{abstract}
Purpose: Concurrent chemoradiation (CCRT) is the standard curative treatment of anal canal cancer (ACC). The role of a brachytherapy (BRT) boost in this setting is still debated. Therefore, the aim of this analysis was to retrospectively evaluate the clinical outcomes in a large cohort of ACC patients treated with CCRT plus BRT boost or external beam radiotherapy (EBRT) boost.

Material and methods: Patients with non-metastatic ACC, treated in our department between January 2003 and December 2014 were included in this analysis. The initial treatment was based on EBRT to the pelvis (prescribed dose, 45 Gy/1.8 Gy) plus concurrent chemotherapy (5-fluorouracil and mitomycin-C). Patients received a pulsed-dose-rate BRT boost on the primary tumor (median dose, $20 \mathrm{~Gy}$; range, 13-25 Gy) 2-3 weeks after the end of CCRT. In patients with contraindications to BRT, an EBRT boost (prescribed dose, 16 Gy, 2 Gy/fraction) was delivered immediately after CCRT.

Results: One-hundred-twenty-three patients were included in this analysis (median age, 61 years; range, 36-93 years; squamous-cell carcinoma, 78\%; HIV+, 6\%; median follow-up, 71 months; range, 2-158 months). The actuarial 5 -year local control (LC), distant metastasis-free survival, colostomy-free survival, and overall survival (OS) rates were $81.7 \%, 92.3 \%, 62.3 \%$, and $74.0 \%$, respectively. At univariate analysis, patients aged $\leq 65$ years $(p<0.010)$, cT1-2 stage $(p=0.004)$, and receiving a BRT boost $(p=0.015)$ showed significantly improved OS. At multivariate analysis, advanced tumor stage cT3-cT4 (HR, 2.12; 95\% CI: 1.09-4.14; $p=0.027)$, and age > 65 years (HR, 3.03; 95\% CI: 1.54-5.95; $p=0.001$ ) significantly predicted increased risk of mortality. The crude rate of toxicity-related colostomies was $4.9 \%$.

Conclusions: The role of BRT boost in ACC remains unclear since the outcomes were not clearly different compared to CCRT alone. However, further improvement of clinical results in ACC treatment is needed, and therefore prospective trials based on advanced (image-guided/adapted) BRT techniques are warranted.
\end{abstract}

J Contemp Brachytherapy 2019; 11, 1: 21-27 DOI: https://doi.org/10.5114/jcb.2019.82804

Key words: anal carcinoma, brachytherapy, colostomy-free survival.

\section{Purpose}

Anal canal cancer $(\mathrm{ACC})$ is a relatively rare malignancy representing about $0.4 \%$ of all new diagnosed neoplasm [1], with an age-adjusted incidence ratio of 0.32 per 100,000 in the US [2]. Over the past decades, perhaps due to increased transmission of HIV and HPV, the incidence has increased without clear improvement in survival even if distant metastases occur in only $5-10 \%$ of cases [3,4].

Concurrent chemoradiation (CCRT) based on external beam radiation therapy (EBRT) plus concurrent 5-fluorouracil (5-FU) and mitomycin-C (MMC) represents the standard treatment option in non-metastatic ACC
Address for correspondence: Milly Buwenge, MSc, Radiation Oncology Center, Department of Experimental, Diagnostic and Specialty Medicine - DIMES, University of Bologna, S. Orsola-Malpighi Hospital, via Giuseppe Massarenti 9, 40138, Bologna, Italy, phone: +39 051 6363564, fax: +39 0516364336 , ๑e-mail: mbuwenge@gmail.com
Received: 10.08.2018

Accepted: 27.01.2019

Published: 28.02.2019 
according to results reported from several randomized trials $[5,6,7,8]$. However, $20 \%$ and $30 \% 5$-year rates of local-regional recurrences and colostomy, respectively, have been reported after CCRT $[8,9]$.

Brachytherapy (BRT) boost has been used to improve these outcomes by delivering a higher and more focused dose to the primary tumor. However, no robust evidence is available on the real advantage produced by a BRT boost after CCRT [10]. Furthermore, most published series were based on the use of low-dose-rate (LDR) BRT and data on the efficacy of pulsed-dose-rate (PDR) are lacking. PDR is a theoretically advantageous BRT technique, since it combines the radiobiological advantages of LDR BRT with the dosimetrical advantages of high-doserate BRT.

Therefore, the aim of this study was to contribute to the current evidence on this issue by retrospectively reviewing a large series of patients with prolonged follow-up, treated with CCRT followed by PDR BRT boost.

\section{Material and methods \\ Study design and objectives}

This was a monocentric retrospective analysis of feasibility and clinical outcomes of CCRT followed by BRT boost in ACC. The study was approved by our institutional review board. Patients $\geq 18$ years with histologically proven non-metastatic ACC with any tumor (T) and nodal $(\mathrm{N})$ stage, treated with CCRT followed by a BRT boost (or EBRT boost if BRT was contraindicated) were eligible for inclusion. Patients with distant metastases or locally recurrent disease and with tumors of the anal margin were excluded.

From January 2003 to December 2014, 185 patients with ACC were treated in our department. Among them, 123 patients were selected according to our inclusion criteria.

\section{Staging and treatment}

Clinical stage was defined according to the American Joint Committee on Cancer criteria [11] by digital rectal examination, anorectal ultrasonography, proctoscopy, computed tomography (CT) scan, and magnetic resonance imaging (MRI). 18F-FDG-PET-CT imaging was used only in a few selected patients with doubtful results after the standard exams.

Patients were first treated with pelvic CCRT. Concurrent continuous infusion of 5 -FU $\left(1,000 \mathrm{mg} / \mathrm{m}^{2} /\right.$ day continuous intravenous infusion for 4 consecutive days in the first and fourth week of EBRT treatment) and MMC $\left(10 \mathrm{mg} / \mathrm{m}^{2} /\right.$ day bolus intravenous infusion on day 1 and 29 of EBRT treatment) were administered. Pelvic EBRT started on the first day of chemotherapy (CHT). The prescribed dose was $45 \mathrm{~Gy}$ (1.8 Gy/fraction). EBRT was planned with 3-dimensional conformal technique using 3 or 4 fields and delivered with a linear accelerator (6-18 MV photon energy) with the patient in prone position. The clinical target volume (CTV) was defined as the gross tumor volume (GTV), the anal canal and the whole mesorectum, internal and external iliac nodes, obturator nodes, and presacral nodes. The GTV extension was evaluated in all patients by transrectal ultrasound. Inguinal nodes were included in the CTV only if metastatic and in patients with cT3-4 ACC or with positive pelvic nodes, according to the Radiation Therapy Oncology Group guidelines. The dose was prescribed and specified according to the International Commission on Radiation Units Measurements report no 50 (ICRU 50) [12].

In 53 patients with positive nodes at clinical staging, a sequential boost was delivered to the involved lymph nodes using multiple fields technique (6-18 MV photons; median dose, 18 Gy; range, 14-20 Gy; 2 Gy/fraction) or with a direct electron beam (20 Gy in 2 Gy/fraction) in case of inguinal nodes.

Clinical response evaluation was performed at the end of CCRT by clinical examination. Patients with cancer involving $>2 / 3$ of the anal canal circumference or with $>1 \mathrm{~cm}$ involvement of perianal skin before CCRT, or with residual disease $>5 \mathrm{~cm}$ in longitudinal or $>1.5 \mathrm{~cm}$ in circumferential direction after CCRT, or with medical contraindication to anesthesia were considered not eligible for BRT and were treated with EBRT boost. EBRT boost was delivered immediately after CCRT with multiple fields technique (16 Gy, $1.8 \mathrm{~Gy} /$ fraction). The BRT boost was delivered 2-3 weeks after CCRT to allow recovery from acute toxicity using ${ }^{192}$ Ir sources. The needles of an active length varying from 5 to $8 \mathrm{~cm}$ depending on the size of the tumor were positioned in parallel, with a distance of $1 \mathrm{~cm}$ interval to ensure adequate dosimetry using a perineal template under general anesthesia. To locate the residual tumor or scar, 1-2 landmarks of silver were inserted. At the end of the implantation prior to insertion of the ${ }^{192} \mathrm{Ir}$ sources, all patients underwent two orthogonal radiograms in order to verify the correct alignment and position of the hollow needles. In case of deviations detectable with this method, the same needles were repositioned. Dose was prescribed and specified based on the Paris system [13] and delivered with 0.67-0.8 Gy/ hour PDR, lasting 24-36 hours. In case of residual disease after CCRT, a BRT boost dose $\geq 20$ Gy was prescribed. If complete clinical response was observed after CCRT, the BRT dose was $\leq 16$ Gy. Furthermore, for $\mathrm{T}_{1-2}$ and $\mathrm{T}_{3-4}$, the median number of charged loaded needles were 5 and 6-7, respectively.

\section{Follow-up}

Follow-up visits were performed by a multidisciplinary team including clinical examination and anorectal ultrasonography every 4 months in the first two years after treatment, every 6 months in the following 3 years, and then yearly. Biopsies under anesthesia were used for differential diagnosis between recurrence and radiation-induced complications, but never before 6 months from the end of the treatment due to the risk of complications and the low probability of early local relapse.

\section{Statistical analysis}

Local control (LC), colostomy-free survival (CFS), distant metastatic-free survival (DMFS), and overall survival (OS) were calculated from the date the treatment started. LC was evaluated considering events clinical- 
ly evident for local-regional ( $\mathrm{T}$ and $\mathrm{N}$ ) disease relapse, persistence, or progression, positive biopsy, and salvage surgery. DMFS was evaluated taking into consideration any treatment failure outside the pelvis. OS was defined as death resulting from any cause. Colostomy-free survival was measured from the day of treatment initiation to colostomy, death, or last follow-up evaluation if the patient was alive with no surgery. Descriptive statistics was used to report patient, tumor, and treatment characteristics. Survival functions were described using the Kaplan-Meier method [14] and compared with log-rank test [15] to investigate differences in OS, LC, CFS, and DMFS between groups defined, based on clinical and pathological factors. Multivariable analysis was performed using Cox's proportional hazard model [16]. Covariates to be introduced in the multivariable models were selected based on backward stepwise strategy ( $p$ inclusion $<0.1$; $p$ exclusion $\geq 0.1$ ). All tests were two-sided and $p$ value $<0.05$ was considered statistically significant. Statistical analysis was performed with SPSS version 22.0 (IBM Corp., Armonk, NY, USA).

Table 1. Patient characteristics of the analyzed cohort with the number of patients' and percentage of the total number of patients [\%]

\begin{tabular}{|c|c|c|}
\hline Variable & Median (range) & No. of patients (\%) \\
\hline Age (years) & $61(36-93)$ & \\
\hline Follow-up (months) & $71(2-158)$ & \\
\hline \multicolumn{3}{|l|}{ Gender } \\
\hline Male & & $30(24.4)$ \\
\hline Female & & $93(75.6)$ \\
\hline \multicolumn{3}{|l|}{ Age (years) } \\
\hline$\leq 65$ & & $71(57.7)$ \\
\hline$>65$ & & $52(42.3)$ \\
\hline \multicolumn{3}{|l|}{ Histology } \\
\hline Squamous & & $96(78.0)$ \\
\hline Cloacogenic & & $8(6.5)$ \\
\hline Basaloid & & $14(11.4)$ \\
\hline Other & & $5(4.1)$ \\
\hline \multicolumn{3}{|l|}{ cT-stage } \\
\hline 1 & & $18(14.6)$ \\
\hline 2 & & $45(36.6)$ \\
\hline 3 & & $41(33.3)$ \\
\hline 4 & & $19(15.4)$ \\
\hline \multicolumn{3}{|l|}{ cN-stage } \\
\hline NO & & $70(56.9)$ \\
\hline N1 & & $28(22.8)$ \\
\hline N2 & & $13(10.5)$ \\
\hline N3 & & $12(9.8)$ \\
\hline \multicolumn{3}{|l|}{ HIV } \\
\hline Positive & & $7(5.7)$ \\
\hline Negative & & 116 (94.3) \\
\hline
\end{tabular}
virus, No-number

\section{Results}

From 123 ACC patients included in this analysis, 116 were treated with CCRT followed by a sequential boost of BRT (102 patients) or EBRT (21 patients), while 7 patients did not receive CT because of advanced age ( $>85$ years, 3 patients), cardiovascular comorbidities (3 patients), and severe herpes zoster infection (1 patient). The median prescribed BRT boost dose was 20 Gy (range, 13-25 Gy). Median follow-up was 71 months (range, 2-158 months). Patients characteristic are summarized in Table 1.

Two-, 5-, and 10-year OS rates were $88.6 \%, 74.0 \%$, and $64.3 \%$, respectively (Figure 1). At univariate analysis, age $\leq 65$ years $(p<0.010)$, initial tumor stage $\mathrm{T}_{1-2}$ $(p=0.004)$, and sequential boost delivered with BRT $(p=0.015)$ were significantly correlated with improved OS (Table 2). At multivariable analysis, patients with $\mathrm{cT}_{3-4}$ stage (HR, 2.12; 95\% CI: 1.09-4.14; $p=0.027)$ and aged $>65$ years $(\mathrm{HR}, 3.03$; 95\% CI: $1.54-5.95 ; p=0.001)$ showed a significantly higher risk of mortality. Table 3 shows LC, CFS, and DMFS stratified for clinical-pathological factor at univariate analysis. Twenty-two patients had local recurrence, more frequently in male patients $(p<0.001)$. Two-, 5-, and 10-year LC was $84.2 \%, 81.7 \%$, and $81.7 \%$, respectively (Figure 2). Considering the large and statistically significant difference in terms of LC between gender, a detailed analysis of this difference in various tumor stage subgroups was performed (Table 4). Our analysis showed that a statistically higher LC rate in female patients was recorded in $\mathrm{T}_{1-2} \mathrm{~N}_{0}$ subjects $(p<0.001)$ with a trend in the $\mathrm{T}_{1-2} \mathrm{~N}_{+}$and in the $\mathrm{T}_{3-4} \mathrm{~N}_{+}$ groups ( $p=0.085$ and $p=0.082$, respectively). Ten patients developed metastases, and 2-, 5-, and 10-year DMFS was 93.3\%, 92.3\%, and 92.3\%, respectively (Figure 3). DMFS rate was higher in patients treated with BRT boost $(p<0.001)$. Two-, 5-, and 10-year CFS was $74.8 \%, 62.3 \%$, and $55.2 \%$, respectively (Figure 4 ). CFS was significantly worse in male patients $(p<0.001)$ and in patients $>65$ years old $(p=0.002)$. Overall, 26 patients underwent colostomy during follow-up (21.1\%). In 20 patients, colostomy was performed because of local recurrence $(16.3 \%)$ and in 6 cases because of treatment-related toxicity $(4.9 \%)$. Colostomy due to treatment-related toxicity was recorded in 5 patients treated with BRT boost $(4.9 \%)$ and in 1 patient treated with EBRT boost (4.8\%).

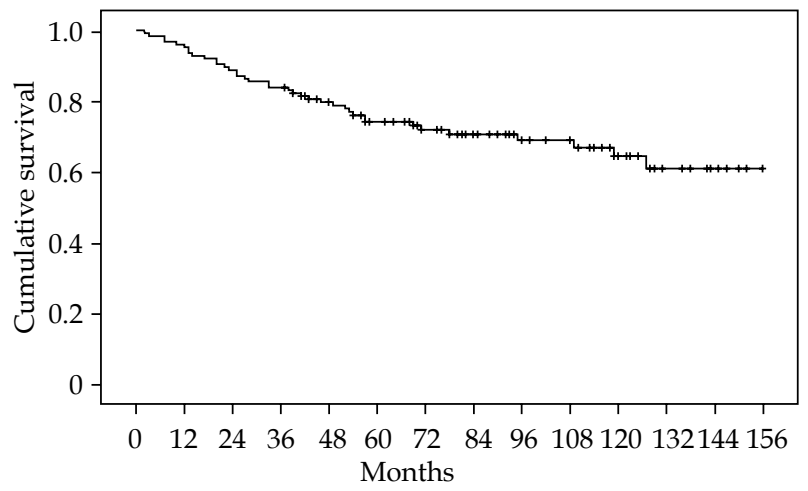

Fig. 1. Overall survival 
Table 2. Univariate analysis including 2- and 5-year overall survival, median survival time, and log-rank $p$-value

\begin{tabular}{|c|c|c|c|c|c|}
\hline Variable & No. of patients & 2-year OS (\%) & 5-year OS (\%) & Median OS (months) & $p$ value \\
\hline \multicolumn{6}{|l|}{ Gender } \\
\hline Male & 30 & 86.7 & 62.2 & $N R$ & \multirow[t]{2}{*}{0.096} \\
\hline Female & 93 & 89.2 & 79.0 & 158 & \\
\hline \multicolumn{6}{|l|}{ Age (years) } \\
\hline$\leq 65$ & 71 & 93.0 & 84.1 & NR & \multirow[t]{2}{*}{$<0.001$} \\
\hline$>65$ & 52 & 82.7 & 62.3 & 119 & \\
\hline \multicolumn{6}{|l|}{ Histology } \\
\hline Squamous & 96 & 87.5 & 74.4 & 158 & \multirow[t]{4}{*}{0.556} \\
\hline Cloacogenic & 8 & 87.5 & 46.7 & 57 & \\
\hline Basaloid & 14 & 92.9 & 85.7 & $N R$ & \\
\hline Other & 5 & 100.0 & 80.0 & NR & \\
\hline \multicolumn{6}{|l|}{ HIV } \\
\hline Positive & 7 & 85.7 & 85.7 & $N R$ & \multirow[t]{2}{*}{0.489} \\
\hline Negative & 116 & 88.8 & 74.4 & 158 & \\
\hline \multicolumn{6}{|l|}{ cT-stage } \\
\hline $\mathrm{T} 1$ & 18 & 100.0 & 88.2 & NR & \multirow[t]{4}{*}{0.020} \\
\hline $\mathrm{T} 2$ & 45 & 95.6 & 81.8 & NR & \\
\hline $\mathrm{T3}$ & 41 & 75.6 & 63.1 & 158 & \\
\hline $\mathrm{T} 4$ & 19 & 89.5 & 66.3 & $N R$ & \\
\hline \multicolumn{6}{|l|}{ cT-stage } \\
\hline $\mathrm{T} 1-2$ & 63 & 96.8 & 83.6 & $N R$ & \multirow[t]{2}{*}{0.004} \\
\hline $\mathrm{T3}-4$ & 60 & 80.0 & 63.9 & 158 & \\
\hline \multicolumn{6}{|l|}{ cN-stage } \\
\hline NO & 70 & 90.0 & 79.5 & $N R$ & \multirow[t]{4}{*}{0.235} \\
\hline N1 & 28 & 96.4 & 73.1 & 78 & \\
\hline $\mathrm{N} 2$ & 13 & 69.2 & 61.5 & 158 & \\
\hline N3 & 12 & 83.3 & 66.7 & 95 & \\
\hline \multicolumn{6}{|l|}{ cN-stage } \\
\hline NO & 70 & 90.0 & 77.9 & $N R$ & \multirow[t]{2}{*}{0.058} \\
\hline N1-N2-N3 & 53 & 86.8 & 68.9 & 109 & \\
\hline \multicolumn{6}{|l|}{ Boost } \\
\hline Brachytherapy & 102 & 91.2 & 78.7 & 158 & \multirow[t]{2}{*}{0.015} \\
\hline External beam RT & 21 & 76.2 & 51.6 & $N R$ & \\
\hline \multicolumn{6}{|l|}{ BRT boost dose (Gy) } \\
\hline$\leq 18$ & 38 & 97.4 & 84.0 & 158 & \multirow[t]{2}{*}{0.284} \\
\hline$>18$ & 64 & 87.5 & 75.8 & $N R$ & \\
\hline \multicolumn{6}{|l|}{ Chemotherapy } \\
\hline No & 7 & 85.7 & 42.9 & 43 & \multirow[t]{2}{*}{0.059} \\
\hline Yes & 116 & 88.8 & 75.9 & 158 & \\
\hline
\end{tabular}

BRT - brachytherapy, HIV - human immunodeficiency virus, No - number, NR - not reached, OS - overall survival, RT - radiotherapy 
Table 3. Univariate analysis including 2- and 5-year colostomy-free survival, local control, metastasis-free survival, and log-rank $p$-value

\begin{tabular}{|c|c|c|c|c|c|c|c|c|c|c|}
\hline Variable & $\begin{array}{c}\text { No. of } \\
\text { patients }\end{array}$ & $\begin{array}{c}\text { 2-year } \\
\text { CFS (\%) }\end{array}$ & $\begin{array}{c}\text { 5-year } \\
\text { CFS (\%) }\end{array}$ & $p$ value & $\begin{array}{l}\text { 2-year } \\
\text { LC (\%) }\end{array}$ & $\begin{array}{l}5 \text {-year } \\
\text { LC (\%) }\end{array}$ & $p$ value & $\begin{array}{c}\text { 2-year } \\
\text { DMFS (\%) }\end{array}$ & $\begin{array}{c}\text { 5-year } \\
\text { DMFS (\%) }\end{array}$ & $p$ value \\
\hline \multicolumn{11}{|l|}{ Gender } \\
\hline Male & 30 & 56.7 & 32.7 & \multirow[t]{2}{*}{$<0.001$} & 69.0 & 56.4 & \multirow[t]{2}{*}{$<0.001$} & 96.2 & 96.2 & \multirow[t]{2}{*}{0.361} \\
\hline Female & 93 & 80.6 & 71.8 & & 91.0 & 89.8 & & 92.4 & 91.1 & \\
\hline \multicolumn{11}{|l|}{ Age (years) } \\
\hline$\leq 65$ & 71 & 81.7 & 71.8 & \multirow[t]{2}{*}{0.002} & 86.8 & 83.7 & \multirow[t]{2}{*}{0.400} & 94.3 & 92.7 & \multirow[t]{2}{*}{0.779} \\
\hline$>65$ & 52 & 63.5 & 48.9 & & 81.9 & 78.8 & & 91.9 & 91.9 & \\
\hline \multicolumn{11}{|l|}{ Histology } \\
\hline Squamous & 96 & 76.0 & 62.1 & \multirow[t]{4}{*}{0.532} & 85.9 & 82.2 & \multirow[t]{4}{*}{0.832} & 92.5 & 91.2 & \multirow[t]{4}{*}{0.782} \\
\hline Cloacogenic & 8 & 50.0 & 50.0 & & 71.4 & 71.4 & & 100.0 & 100.0 & \\
\hline Basaloid & 14 & 78.6 & 78.6 & & 84.6 & 84.6 & & 92.9 & 92.9 & \\
\hline Other & 5 & 80.0 & 60.0 & & 80.0 & 80.0 & & 100.0 & 100.0 & \\
\hline \multicolumn{11}{|l|}{ HIV } \\
\hline Positive & 7 & 75.0 & 62.6 & \multirow[t]{2}{*}{0.717} & 71.4 & 57.1 & \multirow[t]{2}{*}{0.078} & 100.0 & 100.0 & \multirow[t]{2}{*}{0.453} \\
\hline Negative & 116 & 71.4 & 57.1 & & 85.5 & 83.4 & & 92.0 & 91.8 & \\
\hline \multicolumn{11}{|l|}{ cT-stage } \\
\hline $\mathrm{T} 1-2$ & 63 & 81.0 & 64.0 & \multirow[t]{2}{*}{0.006} & 85.7 & 84.0 & \multirow[t]{2}{*}{0.445} & 95.2 & 93.4 & \multirow[t]{2}{*}{0.564} \\
\hline T3-4 & 60 & 68.3 & 49.2 & & 83.2 & 78.9 & & 91.3 & 91.3 & \\
\hline \multicolumn{11}{|l|}{ cN-stage } \\
\hline NO & 70 & 72.9 & 67.1 & \multirow[t]{2}{*}{0.189} & 84.2 & 84.2 & \multirow[t]{2}{*}{0.830} & 94.2 & 94.2 & \multirow[t]{2}{*}{0.387} \\
\hline N1-2-3 & 53 & 77.4 & 55.9 & & 85.4 & 78.4 & & 92.1 & 89.6 & \\
\hline \multicolumn{11}{|l|}{ Boost } \\
\hline BRT & 102 & 77.5 & 65.4 & \multirow[t]{2}{*}{0.198} & 86.1 & 83.9 & \multirow[t]{2}{*}{0.215} & 95.0 & 95.0 & \multirow[t]{2}{*}{0.015} \\
\hline EBRT & 21 & 61.9 & 47.6 & & 75.6 & 68.0 & & 81.7 & 77.0 & \\
\hline \multicolumn{11}{|c|}{ BRT boost dosage (Gy) } \\
\hline$\leq 18$ & 38 & 86.8 & 73.5 & 0.335 & 92.1 & 92.1 & 0.233 & 100.0 & 100.0 & 0.050 \\
\hline$>18$ & 64 & & & & 82.3 & 80.5 & & 91.9 & 91.9 & \\
\hline Chemotherapy & & & & & & & & & & \\
\hline No & 7 & 71.9 & 60.7 & 0.186 & 100.0 & 100.0 & 0.242 & 100.0 & 100.0 & 0.443 \\
\hline Yes & 116 & 85.7 & 42.9 & & 83.7 & 80.7 & & 92.9 & 91.8 & \\
\hline
\end{tabular}

BRT - brachytherapy, CFS - colostomy-free survival, DMFS - distant metastatic-free survival, EBRT - external beam radiotherapy, HIV - human immunodeficiency virus, LC - local control, No - number, NR - not reached

\section{Discussion}

In this retrospective analysis on 123 patients with ACC treated with CCRT followed by PDR BRT boost, the 5 -year rates of LC, CFS, and OS were $81.7 \%, 62.3 \%$, and $74.0 \%$, respectively. Furthermore, the 10 -year rates of LC, CFS, and OS were $81.7 \%, 55.2 \%$, and $64.3 \%$, respectively. Moreover, we recorded a crude rate of $4.9 \%$ of patients receiving colostomy due to treatment-related toxicity.

The study suffers from several limitations: retrospective design, no available data on acute toxicity, no separate analysis of local and regional relapses, lack of description of late toxicity apart from those requiring colostomy, and lack of information about number and site of metastatic nodes.

However, this analysis presents one of the largest available series and the longest follow-up period. Furthermore, to the best of our knowledge, it is the largest series on PDR-based BRT boost in ACC.

Comparing our results with the ones of other series using LDR BRT boost after CCRT [10], the clinical results seem to be quite similar. In particular, in this current study and the series analyzed by Frakulli et al., 5-year LC was $81.7 \%$ vs. $78.6 \%$, CFS was $62.3 \%$ vs. $76.1 \%$, and OS 
Table 4. Univariate analysis comparing local control in male and female patients in different tumor stage subgroups

\begin{tabular}{|c|c|c|c|c|c|c|c|}
\hline \multirow[t]{2}{*}{ Stage } & \multicolumn{2}{|c|}{ Number of patients } & \multicolumn{2}{|c|}{ 2-year local control } & \multicolumn{2}{|c|}{ 5-year local control } & \multirow[t]{2}{*}{$p$ value } \\
\hline & Male & Female & Male & Female & Male & Female & \\
\hline T1-2 NO & 12 & 35 & 58.3 & 97.1 & 58.3 & 97.1 & $<0.001$ \\
\hline T1-2 N1-2-3 & 3 & 13 & 66.7 & 84.6 & 33.3 & 84.6 & 0.085 \\
\hline T3-4 NO & 7 & 16 & 71.4 & 80.8 & 71.4 & 80.8 & 0.649 \\
\hline T3-4 N1-2-3 & 8 & 29 & 71.4 & 92.3 & 57.1 & 88.1 & 0.082 \\
\hline
\end{tabular}

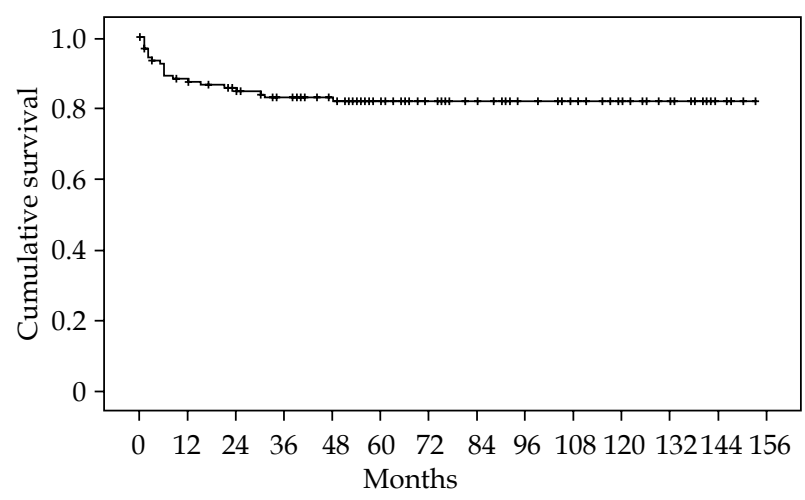

Fig. 2. Local control

was $74.0 \%$ vs. $69.4 \%$. However, it should be noted that our patients had a more unfavorable prognostic profile compared to those included in the review by Frakulli et al. $\left(\mathrm{cT}_{1-2}: 51.2 \%\right.$ vs. $61.0 \% ; \mathrm{cN}_{0}: 56.9 \%$ vs. $72.3 \%$, SCC histology: $78.0 \%$ vs. $94.2 \%$ ). Our crude rate of toxicity-related colostomies was similar to the one presented in the above-mentioned review (4.9\% vs. $3.7 \%)$. In conclusion, based on this data, we cannot draw definitive conclusions about the PDR BRT advantage as boost technique after CCRT.

We also tried to compare our results with those of 5-FU plus MMC arm of the RTOG-9811 randomized trial, where a CCRT dose of 45-59 Gy without BRT boost was prescribed $[8,9]$. Again, the clinical results of our series are similar to those reported in that trial. In particular, in our analysis and in the RTOG-9811 study, 5-year LC was $81.7 \%$ vs. $80.0 \%$, CFS was $62.3 \%$ vs. $71.9 \%$, and OS was $74.0 \%$ vs. $78.3 \%$. Even

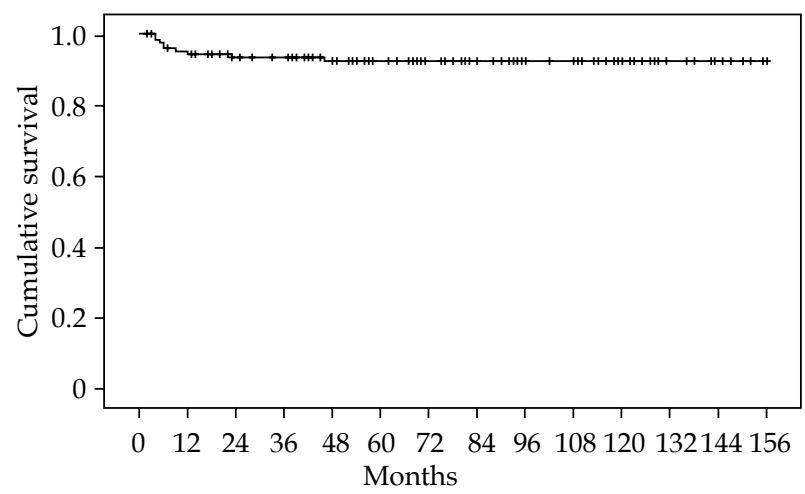

Fig. 3. Distant metastasis-free survival in this case, the comparison is complicated by the different prognostic profile of our series and that of the RTOG trial ( $\mathrm{cT}_{1-2}: 51.2 \%$ vs. $63.0 \%$; $\mathrm{cN}_{0}: 56.9 \%$ vs. $70.0 \%$, SCC histology: $78.0 \%$ vs. $86.0 \%$ ). However, the finding of similar results in an unfavorable prognostic population would lead to the hypothesis of some benefit in patients undergoing BRT boost. A comparison of our treatment-related colostomy rate $(4.9 \%)$ with that of the RTOG trial is complicated because this data was not clearly reported in the two publications $[8,9]$. The authors only stated that the rate of late grade 4 gastrointestinal complications was 3\% without describing the side effects types. However, if we compare the 5-year LC $(80.0 \%)$ with the 5-year CFS $(71.9 \%)$ recorded in the RTOG trial $[8,9]$, we can hypothesize that the rate of colostomies due to toxicity was not negligible and probably almost similar to the one recorded in our series.

In the last 5 years, some studies on the use of IMRT-SIB in this setting have been published $[17,18,19,20,21]$. The use of IMRT is promising, since a reduction in acute toxicity has been demonstrated with the use of this technique. Furthermore, the use of IMRT-SIB allows the delivery of an increased total dose and dose per fraction on the macroscopic tumor. Therefore, this technique is potentially useful to intensify the effect of CCRT as an alternative to BRT boost. However, the efficacy of IMRT-SIB is hardly comparable with our case series, since all publications reported results with a shorter timing ( $<5$ years). The only data that can be observed even with this modern technique is the reported rate of around $4 \%$ of treatment-related colostomies due to toxic effects $[20,21]$.

In our series, we observed (as expected in a tumor with relatively favorable prognosis) a worse OS in older

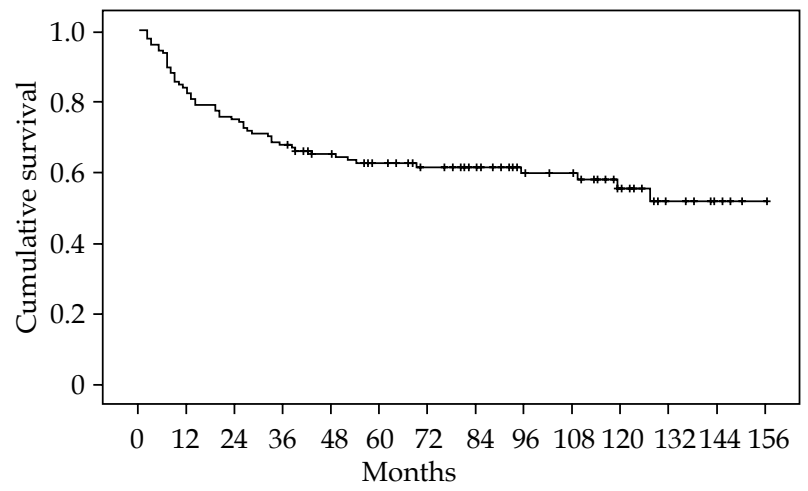

Fig. 4. Colostomy-free survival 
patients. Furthermore, significantly higher DMFS and OS rates were recorded at univariate analysis in patients undergoing BRT boost compared to EBRT boost. This result could be attributed to a probably larger tumor volume in patients treated with EBRT technique, even if we cannot confirm this hypothesis due to lack of data on tumor volume or simply tumor diameter. We also observed significantly lower CFS rate in male patients as described by Franco et al. [17] and significantly lower LC in the same patients. A negative prognostic effect of male gender was previously reported also in the RTOG 9811 trial [9].

Another interesting result of our analysis is that 5-year and 10-year rates of LC and DMFS were identical. This data would suggest that late ACC relapses are very rare.

Two groups reported the results of small series, presenting very preliminary data on IGBT/IABT-based BRT boost in ACC $[22,23]$. In the first study, 11 patients underwent CCRT followed by BRT boost (total EQD $2,60 \mathrm{~Gy}$ ) that was planned with multi-parametric MRI. With 25 months median follow-up, Tagliaferri et al. reported 91\% LC (crude rate), without cases of grade $>2$ late toxicity [22]. Similarly, Kapoor et al. treated 16 patients with CT-based IGBT boost and reported $87.5 \%$ 2-year LC rate and no cases of grade $>2$ late toxicity (median follow-up, 41 months) [23].

In conclusion, based on the retrospective design and other limitations of our analysis, we cannot recommend the routine prescription of a BRT boost in clinical practices. However, there is a need for further improvement of the results of ACC treatment, where clinical outcomes did not change significantly in the last decades. Therefore, further evaluation of this technique, with the aim to improve its efficacy and safety, is warranted. The use of IGBT techniques in combination with IMRT-based irradiation of the pelvic and inguinal volumes should be tested in well-designed prospective trials. In order to favor treatment modulation with tailored techniques and doses, it is necessary that future studies will describe in detail the results stratifying them based on the characteristics of the neoplasm and particularly, in terms of stage and histology.

\section{Disclosure}

Authors report no conflict of interest.

\section{References}

1. National Cancer Institute. SEER cancer statistics factsheets: anal cancer. http://seer.cancer.gov/statfacts/html/anus. html. Accessed September 24, 2014.

2. https://seer.cancer.gov/statfacts/html/anus.html. Accessed July 29, 2018.

3. Siegel R, Ward E, Brawley O, Jemal A. Cancer statistics, 2011: the impact of eliminating socioeconomic and racial disparities on premature cancer deaths. CA Cancer J Clin 2011; 61: 212-236.

4. Rousseau DL, Thomas CR, Petrelli NJ, Kahlenberg MS. Squamous cell carcinoma of the anal canal. Surg Oncol 2005; 14: 121-132.

5. Epidermoid anal cancer: Results from the UKCCCR randomised trial of radiotherapy alone versus radiotherapy, 5-fluorouracil, and mitomycin. UKCCCR Anal Cancer Trial Working Party. UK Co-ordinating Committee on Cancer Research. Lancet 1996; 348: 1049-1054.
6. Bartelink H, Roelofsen F, Eschwege F et al. Concomitant radiotherapy and chemotherapy is superior to radiotherapy alone in the treatment of locally advanced anal cancer: Results of a phase III randomized trial of the European Organization for Research and Treatment of Cancer Radiotherapy and Gastrointestinal Cooperative Groups. J Clin Oncol 1997; 15: 2040-2049.

7. Flam M, John M, Pajak TF et al. Role of mitomycin in combination with fluorouracil and radiotherapy, and of salvage chemoradiation in the definitive nonsurgical treatment of epidermoid carcinoma of the anal canal: Results of a phase III randomized intergroup study. J Clin Oncol 1996; 14: 2527-2539.

8. Ajani JA, Winter KA, Gunderson LL et al. Fluorouracil, mitomycin, and radiotherapy vs fluorouracil, cisplatin, and radiotherapy for carcinoma of the anal canal: A randomized controlled trial. JAMA 2008; 299: 1914-1921.

9. Gunderson LL, Winter KA, Ajani JA et al. Long-term update of US GI intergroup RTOG 98-11 phase III trial for anal carcinoma: survival, relapse, and colostomy failure with concurrent chemoradiation involving fluorouracil/mitomycin versus fluorouracil/cisplatin. J Clin Oncol 2012; 30: 4344-4351.

10. Frakulli R, Buwenge $M$, Cammelli $S$ et al. Brachytherapy boost after chemoradiation in anal cancer: a systematic review. J Contemp Brachytherapy 2018; 10: 246-253.

11. Amin MB, Edge S, Greene F et al. (Eds.). AJCC Cancer Staging Manual (8th edition). Springer International Publishing: American Joint Commission on Cancer. 2017.

12. International Commission on Radiation Units and Measurements ICRU Report 62. Prescribing, recording, and reporting photon beam therapy (Supplement to ICRU Report 50), ICRU, Bethesda, MD (1999).

13. Dutreix A, Marinello G. The Paris system. In: Pierquin B, Wilson JF, Chassagne D (eds.). Modern brachytherapy. Masson, New York 1987; 25-42.

14. Kaplan E, Meier P. Nonparametric estimation from incomplete observations. Am J Stat Assoc 1958; 53: 457-481.

15. Peto R, Peto J. Asymptotically efficient rank invariant procedures. J R Stat Soc 1972; 135: 185-207.

16. Cox DR. Regression models and life tables (with discussion). Journal of the Royal Statistical Society, Series B 1972; 74: 187-220.

17. Franco P, Arcadipane F, Ragona R et al. Locally advanced (T3-T4 or $\mathrm{N}+$ ) anal cancer treated with simultaneous integrated boost radiotherapy and concurrent chemotherapy. Anticancer Res 2016; 36: 2027-2032.

18. Franco P, Arcadipane F, Ragona R et al. Early-stage node-negative (T1-T2N0) anal cancer treated with simultaneous integrated boost radiotherapy and concurrent chemotherapy. Anticancer Res 2016; 36: 1943-1948.

19. Janssen $S$, Glanzmann $C$, Bauerfeind $P$ et al. Clinical experience of SIB-IMRT in anal cancer and selective literature review. Radiat Oncol 2014; 9: 199.

20. Tomasoa NB, Meulendijks D, Nijkamp J et al. Clinical outcome in patients treated with simultaneous integrated boost-intensity modulated radiation therapy (SIB-IMRT) with and without concurrent chemotherapy for squamous cell carcinoma of the anal canal. Acta Oncol 2016; 55: 760-766.

21. Zimmermann M, Beer J, Bodis S et al. PET-CT guided SIB-IMRT combined with concurrent 5-FU/MMC for the treatment of anal cancer. Acta Oncol 2017; 56: 1734-1740.

22. Tagliaferri L, Manfrida S, Barbaro B et al. MITHRA - multiparametric MR/CT image-adapted brachytherapy (MR/ CT-IABT) in anal canal cancer: a feasibility study. J Contemp Brachytherapy 2015; 7: 336-345.

23. Kapoor R, Khosla D, Shukla AK et al. Dosimetric and clinical outcome in image-based high-dose-rate interstitial brachytherapy for anal cancer. Brachytherapy 2014; 13:388-393. 